\title{
Crigler-Najjar Syndrome: An Unusual Course with Development of Neurologic Damage at Age Eighteen
}

\author{
Terrence F. Blaschke, Paul D. Berk, ${ }^{[82]}$ Bruce F. Scharschmidt, J. Roy Guyther, \\ John M. Vergalla, and Jeanne G. Waggoner
}

\begin{abstract}
Metabolism Branch, National Cancer Institute, and Section on Diseases of the Liver, National Institute of Arthritis, Metabolism and Digestive Diseases, National Institutes of Health, Bethesda, Maryland; and Village Medical Center, Mechanicsville, Maryland, USA
\end{abstract}

\section{Extract}

A patient with type I congenital nonhemolytic jaundice (type I Crigler-Najjar syndrome (CNJ)), who first developed overt neurologic signs at age 18, is reported. Studies with isotopic bilirubin, performed both when she was well and after the onset of brain damage, demonstrated normal hepatic bilirubin uptake and storage capacity, and normal bilirubin turnover $(3.0 \mathrm{mg} / \mathrm{kg} / 24 \mathrm{hr})$. As a result of a virtual absence of conjugation, net bilirubin clearance was reduced to $0.0075 \mathrm{ml} / \mathrm{min} / \mathrm{kg}$, which is approximately $1 \%$ of normal $(0.65 \pm 0.18 \mathrm{ml} / \mathrm{min} / \mathrm{kg})$. Therapy with glutethimide, phenobarbital, blue light, and oral agar were all ineffective in reducing the concentration of unconjugated bilirubin in plasma or accelerating radiobilirubin disappearance.

The acute onset of neurologic disease occurred at age 18, and may possibly have related to a transient increase in the molar bilirubin to albumin ratio to a value greater than 1.0. Exchange plasmapheresis, performed with a continuous flow centrifuge, rapidly reduced the bilirubin concentration in plasma from 41 to $6 \mathrm{mg} / 100$ $\mathrm{ml}$, and was associated with apparent clinical improvement. A total of $1,900 \mathrm{mg}$ bilirubin was removed by this procedure.

Although in vivo phototherapy was ineffective, in vitro illumination of the patient's plasma with special blue lamps produced a rapid fall in the bilirubin concentration in plasma. Bilirubin was converted to polar, diazo-negative derivatives by a process in which several steps could be distinguished. The initial photodegradation products were colored, tightly albumin bound and nondialyzable, which explained their tendency to be excreted in the bile in preference to the urine. Continued illumination for up to $24 \mathrm{hr}$ resulted in the production of colorless, nonalbumin-bound compounds which, when injected into rats, were excreted principally in the urine.

\section{Speculation}

Pending the perfection of techniques for auxiliary hepatic transplantation in man, extracorporeal phototherapy or hemoperfusion over albumin-conjugated agarose columns may provide a means of prevention of the otherwise inevitable development of neurologic disease in patients with type I CNJ. 


\section{Introduction}

Type I CNJ, first described in 1952 by Crigler and Najjar [24], is a rare autosomal recessive disorder characterized by severe unconjugated hyperbilirubinemia. In patients with CNJ of this type, death usually occurs in early infancy as a result of neurologic damage. AIthough there have been occasional reports of patients with type I GNJ who have temporarily avoided the onset of neurologic deterioration, only one individual $(J D H)$ reported previously managed to survive symptom-free beyond puberty. This patient dies subsequently of rapidly progressive neurologic disease at age $16[18,27]$.

The present paper describes a case of type $I$ CNJ in a relative of $J D H$. The course of her disease has been remarkably similar to that of $J D H$, with the onset of symptomatic neurologic deterioration developing at age 18. The onset of symptoms, while she was being followed at the National Institutes of Health, has provided a unique opportunity for further investigations of the pathogenesis and therapy of this disorder.

\section{Case History}

$M E H$, a 19-year-old Caucasian female, is a double first cousin of $J D H$, one of the seven original patients with type I CNJ described by Crigler and Najjar [24]. An abbreviated family tree, illustrating the extensive con-

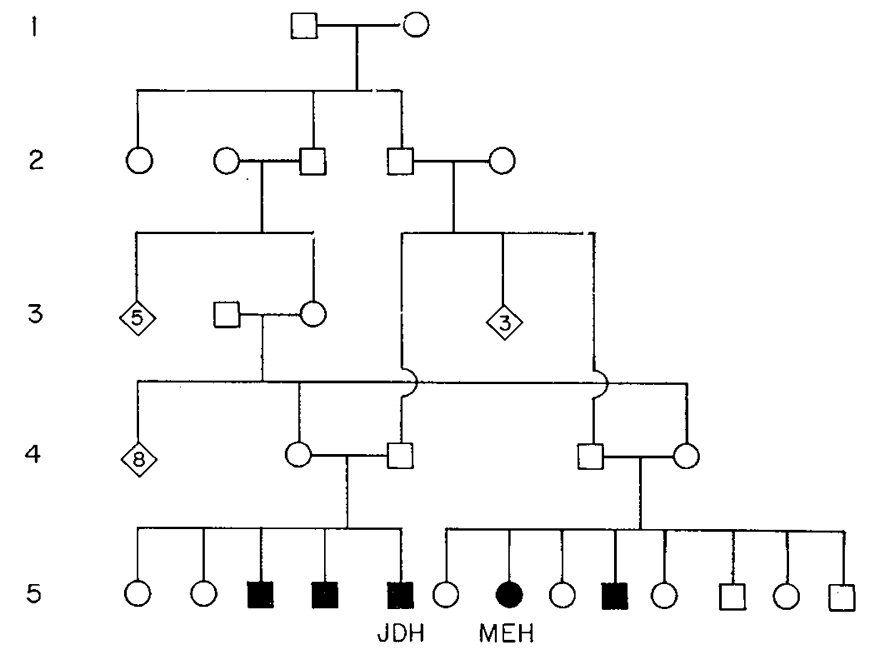

Fig. 1. An abbreviated pedigree demonstrating consanguinity in the family of $M E H$. A more extensive pedigree, complete as of 1952, was included in the original report of Crigler and Najjar [24]. $J D H$, a double first cousin of $M E H$, also escaped kernicterus in infancy, only to dic of neurologic damage at age $16[18,27]$. Numbers within diamonds on this pedigree refer to groups of phenotypically normal individuals. sanguinity present in this family, is shown in Figure 1. The kindred, an early American family living in the relatively isolated peninsular counties of the western shore of southern Maryland, have been extensively investigated by McKusick [41]. In addition to type I CNJ, four other recessively inherited disorders, homocystinuria, Morquio's syndrome, metachromatic leukodystrophy, and bird-headed dwarfism, have been found in this family group.

$M E H$ was the 3,370 -g product of an uneventful pregnancy and delivery. Jaundice was noted shortly after birth. She became increasingly icteric within the first few days of life and has remained so until the present time. Because of the patient's jaundice and her family history, she was seen on four occasions during early childhood at Johns Hopkins Hospital, where physical examination and laboratory data were unremarkable with the exception of jaundice caused by severe unconjugated hyperbilirubinemia, averaging 25 $\mathrm{mg} / 100 \mathrm{ml}$. During one of these visits, defective glucuronide formation was demonstrated using several nonbilirubin aglycones. The family subsequently declined to permit more extensive evaluation. Results of these studies and her early course have been published previously $[20,21]$.

During the remainder of her childhood and adolescence, despite persistent unconjugated hyperbilirubinemia of between 20 and $35 \mathrm{mg} / 100 \mathrm{ml}$, she grew and developed normally, made satisfactory progress in school, and went through the usual childhood diseases, including measles and pertussis, without untoward sequellae. Menarche was at age 14 and was followed by a normal menstrual pattern. Throughout much of this period her older cousin, $J D H$, also appeared to be doing well, with no evidence of the neurologic disease which usually results in early death in patients affected with this disorder. However, in $1965 \mathrm{JDH}$ died unexpectedly at age 16 of rapidly progressive neurologic symptoms which resembled kernicterus [18, 27], and the patient and her family eventually decided to seek further medical advice.

$M E H$ was seen initially in the outpatient department of the National Institutes of Health (NIH) in August 1970, and was admitted subsequently to the Clinical Center in April 1971 for a period of 10 weeks. Her physical examination, which included an extensive neurologic examination, was within normal limits except for deeply orange-yellow skin and sclerae. Hematologic data were unremarkable, with a hemoglobin of 13.5 $\mathrm{gm} / 100 \mathrm{mI}$, hematocrit $41 \%$, and leucocyte count 7,300 
with a normal differential. Erythrocyte survival, using autologous ${ }^{51}$ Cr-labeled cells, was 26.4 days (normal $\geqslant 26$ days). Routine liver function studies revealed serum glutamic oxalacetic transaminase (SGOT) 41, serum glutamic pyruvic transaminase (SGPT) 31, alkaline phosphatase $59 \mathrm{IU}$, albumin $3.5 \mathrm{gm} / 100 \mathrm{ml}$, and a normal prothrombin time. An oral cholecystogram was also normal. Concentration of bilirubin in plasma ranged between 18 and $30 \mathrm{mg} / 100 \mathrm{ml}$, and was virtually all indirect reacting. Despite the absence of clinical neurologic abnormalities, her electroencephalogram (EEG) was abnormal on two occasions, showing a diffusely and moderately slow background with paroxysmal bursts of high voltage 3-5/sec activity. Psychologic testing revealed an overall impression of normal intelligence, and her score of 79 on the Slossen Intelligence Test was felt by the psychologist to be caused by cultural factors in large measure.

During this first admission attention was directed primarily toward attempting to find a practical means of reducing the concentration of unconjugated bilirubin in the patient's plasma, in the hope of preventing the development of clinically overt neurologic damage. She was given several weeks of treatment with phenobarbital and glutethimide, both known to reduce the concentration of unconjugated bilirubin in plasma effectively in a variety of other conditions $[1,13,15,23$, $68,69]$. She failed to respond to either agent with either a reduction in concentration of bilirubin in plasma or a significant change in the rate of excretion of radiobilirubin (see below). She was unable to tolerate a trial of cholestyramine [37] because of nausea and vomiting. At the time of her discharge in May 1971 there had been no change in her clinical or biochemical variables. Subsequently, in July 1971, a 4-day trial of phototherapy was attempted. During this trial, the patient was exposed to intense direct summer sunlight while wearing a fashionably small two-piece bathing suit for 6-8 hr daily. Plasma bilirubin concentration, which was determined immediately before and after each exposure, fell by an average of only $0.5 \mathrm{mg} / 100$ ml during each day's experiment, and had usually returned to baseline levels by the subsequent morning.

She was married in July 1971 and an IUD was inserted in order to avoid any possible detrimental effects of pregnancy or oral contraceptives. Genetic counseling was given. She was then lost to follow-up for 6 months. When next seen in January 1972, at age 18 , her family gave a history of $1-2$ months of progressive withdrawal and bizarre behavior which was fol- lowed by speech difficulty, motor incoordination and, finally, a grand mal seizure. No unusual precipitating event could be ascertained. She was readmitted to the Clinical Center.

At the time of this admission her general physical examination was unchanged, but her neurologic status had markedly deteriorated, with examination revealing difficulty with walking, speech, and coordination as well as athetoid movements, lapses of awareness, and frequent minor motor seizures. There also appeared to be marked intellectual deterioration. However, the persistent seizure activity made it difficult to be certain how much of the apparent intellectual loss was post-ictal. Her EEG was now severely abnormal, showing diffuse dysrhythmia and abundant epileptiform activity without definite focal or lateralizing features. A lumbar puncture, which had not been performed previously, showed only slightly yellow cerebrospinal fluid with a bilirubin level of $0.2 \mathrm{mg} / 100$ $\mathrm{ml}$. Other laboratory values were unremarkable except for a total serum bilirubin level of $34-36 \mathrm{mg} / 100 \mathrm{ml}$. Although higher than during her initial NIH admission, this value was within the range which she had run for many years. The serum albumin on admission was $3.9 \mathrm{~g} / 100 \mathrm{ml}$. Diphenylhydantoin and phenobarbital therapy was begun for seizure control.

Because of the relatively recent and abrupt deterioration of the patient's neurologic status, it was decided to reduce her bilirubin concentration in plasma quickly by exchange plasmapheresis. This had the twofold rationale that $(1)$ this procedure might promote the return to the plasma of bilirubin in a critical central nervous system location; and (2) if there were only a transient failure of the blood-brain barrier for bilirubin, then reducing the bilirubin concentration in plasma (and thus the total amount of unconjugated bilirubin not bound to plasma proteins) might minimize additional central nervous system damage. We were encouraged to proceed with exchange plasmapheresis by reports indicating that exchange transfusion could dramatically, if transiently, reduce bilirubin concentration in plasma of infants with CNJ [35], and by the common clinical observation that abrupt reduction of bilirubin concentration in plasma of neonates with kernicterus of recent onset was often followed by marked improvement in the neurologic abnormalities.

On the morning of her 3rd hospital day bilirubin concentration in plasma was $36 \mathrm{mg} / 100 \mathrm{ml}$ (Fig. 2). An indwelling arterial line was inserted [72] in the left 


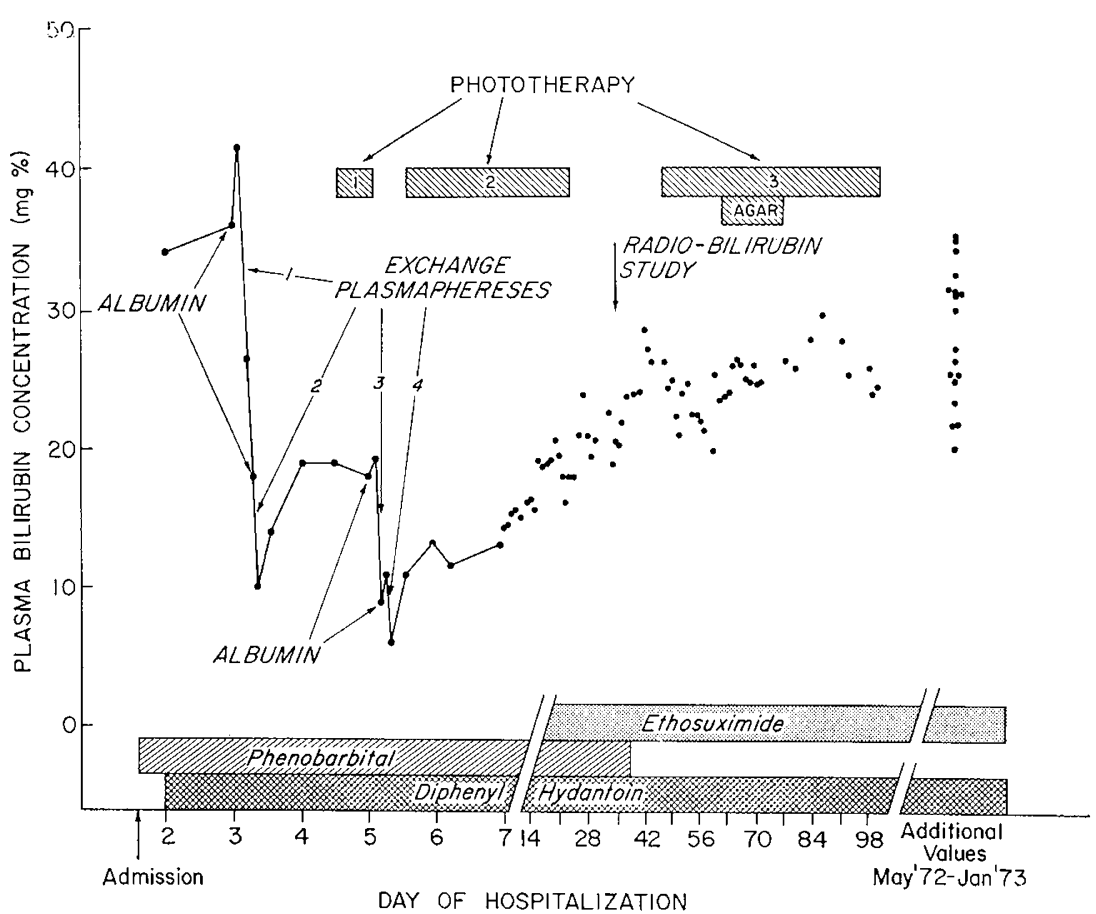

Fig. 2. The clinical course of $M E H$ during her 1972 admission. Exchange plasmapheresis rapidly reduced the bilirubin concentration in plasma from 36 to $6 \mathrm{mg} / 100 \mathrm{ml}$. Note that the infusion of albumin, $1 \mathrm{~g} / \mathrm{kg}$, before each exchange plasmapheresis, temporarily increased the bilirubin concentration in plasma, presumably by mobilizing extravascular bilirubin. Phenobarbital, diphenylhydantoin, and ethosuximide were administered for seizure control and are not believed to have significantly influenced the bilirubin levels in plasma. However, neurologic improvement coincident with reduction of the bilirubin concentration may partially reflect simultaneous improvement in seizure control. Neither phototherapy nor oral agar, administered during the radiobilirubin study, appreciably influenced either the plasma bilirubin concentration or the radiobilirubin half-life.

radial artery, and connected to the inflow of an IBM/ NCI [72] continuous flow blood cell separator [29, 73]. The venous return was to a vein in the right antecubital fossa. A priming dose of human albumin $(\simeq 1.0 \mathrm{~g} / \mathrm{kg})$ was given intravenously, which, after a 2 -hr period of equilibration, resulted in an increase in bilirubin concentration in plasma to $41 \mathrm{mg} / 100 \mathrm{ml}$ (Fig. 2). At this point, the patient was anticoagulated with heparin, and blood flow through the continuous flow centrifuge was begun at $60 \mathrm{ml} / \mathrm{min}$. Formed elements (erythrocytes, leucocytes, and platelets) were separated from the patient's plasma and resuspended in normal fresh or fresh frozen plasma before reinfusion to the patient. The patient's own plasma was discarded. At the completion of the first 3-liter exchange plasmapheresis, an additional dose of albumin was given, and after another equilibration period, a second 3-liter plasma exchange was performed. At the completion of the second exchange, the bilirubin concentration in plasma was $10.0 \mathrm{mg} / 100 \mathrm{ml}$ (Fig. 2). Five hours later the bilirubin concentration in plasma had risen to $14 \mathrm{mg} / 100$ $\mathrm{ml}$, and by the subsequent morning it was $19.0 \mathrm{mg} / 100$ ml. Because of the rapid rebound in bilirubin concentration, phototherapy was instituted, using an adultsized phototherapy apparatus improvised from x-ray viewboxes, and containing standard daylight fluorescent light bulbs. Coincident with the institution of phototherapy, the bilirubin concentration in plasma stabilized over the next $24 \mathrm{hr}$, during which time fresh and fresh-frozen plasma sufficient to perform two more 3-liter plasma exchanges was accumulated. These additional exchanges were performed on the 5th hospital day. The total quantity of bilirubin removed during the 2 days of exchange plasmapheresis was $1,900 \mathrm{mg}$.

The bilirubin concentration was $6 \mathrm{mg} / 100 \mathrm{ml}$ at the end of the final exchange on the 5th hospital day, and was $13.2 \mathrm{mg} / 100 \mathrm{ml}$ on the following morning (hospital day 6) after $12 \mathrm{hr}$ of phototherapy overnight with a new, specially designed bank of eight Westinghouse [74] Special Blue (F20 T12/BB) fluorescent phototherapy lamps mounted 12 inches above the patient's bed. Spinal fluid bilirubin at this time was reported as negative, although the fluid appeared minimally xanthochromic. Phototherapy with this new apparatus 
was administered for 8-12 hr daily for 16 days after the plasma exchanges, during which time the bilirubin concentration gradually rose to $19-20 \mathrm{mg} / 100 \mathrm{ml}$ (Fig. 2).

Immediately after the plasma exchanges, there appeared to be a marked improvement in the patient's general level of alertness and responsiveness. Although this was coincident with the reduction in bilirubin levels, it also coincided with a marked improvement in control of seizure activity, both clinically and on EEG, which resulted from changes in her antiseizure regimen. This was accompanied by an improvement in all aspects of the neurologic examination, although her condition stabilized with moderately severe neurologic deficits. On the 19th hospital day, a neurologic consultant [75] noted the following significant findings: (1) marked decrease in facial expression and movement disorder characterized by severe bradykinesia, suggestive of basal ganglion disease; (2) striking hyperreflexia, indicative of pyramidal system damage; (3) poor performance of rapid alternating movements, which indicated possible cerebellar dysfunction; and (4) myoclonic jerks. On the same day, nausea, which had been present for several days, since the institution of ethosuximide therapy, worsened, and the patient vomited several times. Mild diarrhea, present since the exchange transfusions and the institution of phototherapy, also increased and several massive diarrheal stools were passed. On the subsequent day she was febrile to $40.4^{\circ}$, and Klebsiella was grown from her bloodstream and, in almost pure culture, from her stool. The leucocyte count was 21,000 with $81 \%$ granulocytes. Phototherapy was discontinued, treatment was begun with intravenous Kelflin and Kanamycin on the basis of preliminary sensitivity studies, and over the subsequent 6 days temperature and leucocyte count returned to normal and all abdominal signs and symptoms disappeared. Antibiotics were discontinued after 2 weeks, on the 34 th hospital day.

On the 18th hospital day, the alkaline phosphatase level, which had always been normal (<78 IU) was elevated (91 IU), reaching a maximum of $250 \mathrm{IU}$ on the 39 th hospital day. Serum transaminases became elevated on the 21st hospital day, and peaked (SGOT $=128$, SGPT $=133$ ) on the 27th hospital day. Transaminases had returned to normal before discharge on the 128th hospital day, but the alkaline phosphatase has been chronically elevated, in a range from 86-108 IU, through January 1973. A percutaneous liver biopsy, obtained on the 45th hospital day, was normal except for a very minimal round cell infiltrate in some of the portal triads. Repeated blood samples failed to detect either HBAg or anti-HBAg, and all of the plasma used for the plasma exchanges was negative for HBAg. The specific etiology for the elevated transaminases could not be established. Although the course is most compatible with transfusion-transmitted short incubation (A virus) hepatitis, the concomitant existence of gram-negative sepsis cannot be ruled out as a cause for the abnormalities observed.

On the 36 th hospital day, a radiobilirubin disappearance study was begun (see below); phototherapy, $12 \mathrm{hr} / 24 \mathrm{hr}$, was resumed on the 46th hospital day; and oral agar, USP, $40 \mathrm{~g} / 24 \mathrm{hr}$ was added to the regimen on the 60 th day [54]. Neither form of treatment influenced the bilirubin concentration, which ranged from $24-27 \mathrm{mg} / 100 \mathrm{ml}$ (Fig. 2). Agar was abandoned after 2 weeks, but phototherapy was continued until discharge on the 128th day after admission (May 26, 1972).

The patient has been seen regularly in the outpatient department of the NIH. Between May 1972 and January 1973, her neurologic status fluctuated somewhat from visit to visit, but showed no downward trend. She continued to exhibit some seizure activity and all of the deficits previously described, but her gait has clearly improved and she is once again able to care for herself in most respects. Bilirubin levels during this time fluctuated from $25.5-34.3 \mathrm{mg} / 100 \mathrm{ml}$ and, at least subjectively, appeared to correlate roughly with her neurologic status. Serum albumin concentration ranged from 3.6-4.1 g/100 ml during the same period. At the time the bilirubin was 34.3, the patient's neurologic status was marginally worse, but she refused hospitalization for plasma exchange. Her bilirubin was lower and her performance improved without specific treatment during subsequent outpatient visits.

\section{Special Studies}

\section{In Vivo}

Studies of plasma radiobilirubin kinetics. The plasma disappearance curve of unconjugated radiobilirubin was determined on two occasions: in January 1971 when she was well, using $\left({ }^{14} \mathrm{C}\right)$ bilirubin [3], and in February 1972, after the onset of neurologic disease, with $\left({ }^{3} \mathrm{H}\right)$ bilirubin $[30]$. Both studies were performed as described previously $[9,17]$. For the initial study in 1971, multiple points were obtained during the first 24 hr, followed by daily samples for 69 days. All of the data from the initial 12-day control period were then 
subjected to computer analysis in terms of a threecompartment model of bilirubin metabolism reported previously [9, 17]. Hepatic storage capacity of bilirubin was estimated from the result of the compartmental analysis by the method of Quarfordt et al. [57]. In addition, the terminal half-life of the disappearance curve for bilirubin in plasma, the total miscible bilirubin pool, and daily bilirubin turnover were determined by computer for the 12-day control period [62]. The terminal $\mathrm{t}_{1 / 2}$ was also measured during an 18-day period of phenobarbital administration, and a period of glutethimide administration of 22 days' duration. For the 1972 study, insufficient data were obtained within the first 8 hr for detailed compartmental analysis; however, the total miscible bilirubin pool, the terminal $t_{1 / 2}$, and daily bilirubin turnover were calculated during a control period [76], and the $t_{1 / 2}$ was determined during periods of phototherapy and oral agar administration also.

Carbon monoxide production. In 1971 endogenous carbon monoxide production, which provides an independent estimate of total body heme turnover [22], was measured during a base-line period and during phenobarbital and glutethimide treatment, using a closed rebreathing system. Details of the system used and analytic methods employed have been reported previously [10].

Studies of organic anion transport. Sulfobromophthalein (BSP) and indocyanine green clearances were determined using techniques and methods of data analysis described previously [6] as a further test of organic anion clearance by the liver. These studies were performed on three occasions in 1971, during a control period and periods of phenobarbital and glutethimide administration, in order to examine whether there were defects in the transport of organic anions other than bilirubin in $\mathrm{CNJ}$.

Studies of glucuronide formation. Studies of salicylamide metabolism were performed in 1971, before and after glutethimide and phenobarbital treatment, using an oral salicylamide load of $1 \mathrm{~g}$, to test the conjugating capacity of the liver for substances which are metabolized primarily by glucuronidation. Urine collection and determination of both glucuronide and nonglucuronide conjugates were carried out as described by Song et al. [64, 77]. Hepatic bilirubin UDP. glucuronyltransferase was measured in a portion of the 1972 percutaneous liver biopsy specimen, using the method of Black and Billing [12].

\section{In Vitro}

Although in vivo phototherapy failed to lower the concentration of bilirubin in plasma appreciably, published reports $[16,49,56]$ indicated that illumination of bilirubin in plasma in vitro is highly effective in reduction of bilirubin levels. We considered the possibility that, with the use of the IBM/NCI [72] cell separator, the patient's plasma could be subjected to extracorporeal phototherapy. In order to test this possibility the following studies were carried out.

Five 4-inch blood warming coils (Abbott [78], no. 1663) with a total volume of $250 \mathrm{ml}$ were connected in series around two Westinghouse [74] Special Blue (F20T12/BB) fluorescent light bulbs (Fig. 3). Aliquots of $350-500 \mathrm{ml}$ plasma from $M E H$, obtained during exchange plasmapheresis and labeled with either $\left({ }^{14} \mathrm{C}\right)$ or $\left({ }^{3} \mathrm{H}\right)$ bilirubin, or corresponding volumes of artificial jaundiced plasma $(17.4 \mathrm{mg} / 100 \mathrm{ml}$ unconjugated bilirubin, labeled with $\left({ }^{14} \mathrm{C}\right)$ bilirubin, in $4 \%$ human albumin buffered to $\mathrm{pH}$ 7.2) were circulated through these coils from a darkened, magnetically stirred reservoir by means of a peristaltic pump at flow rates of 10-12 $\mathrm{ml} / \mathrm{min}$. Samples of plasma were obtained from the reservoir at frequent intervals and examined for $(l)$ the partitioning of both diazotizable bilirubin and radioactivity between the lower (nonpolar or unconjugated bilirubin) and upper (polar or conjugated bilirubin) layers of a Weber-Schalm partition system [70]; and (2) the appearance of photodegradation products of bilirubin, which were crudely estimated from the magnitude of a small, broad new absorption band, with a maximum at $565 \mathrm{~nm}$, in the illuminated plasma samples.

Protein binding of the in vitro bilirubin photodegradation products was examined in the following ways: by quantitation of the precipitation of radioactivity in illuminated plasma samples after the precipitation of proteins with either $10 \%$ trichloroacetic acid or rat antihuman albumin; by determination of the percentage of radioactivity in plasma samples which could be dialyzed across a cellophane membrane into various ionic strengths of phosphate buffer, $\mathrm{pH} 7.2$; and by determination of both the percentage of radioactivity which would be transferred from $1 \mathrm{ml}$ plasma to a 5-ml albumin-conjugated agarose column containing $50 \mathrm{mg}$ human serum albumin/g wet wt gel [53], and the conditions required for elution from the columns. Possible physiologic significance of changes of protein binding was assessed by determining the relative recovery of radioactivity into bile and urine over 


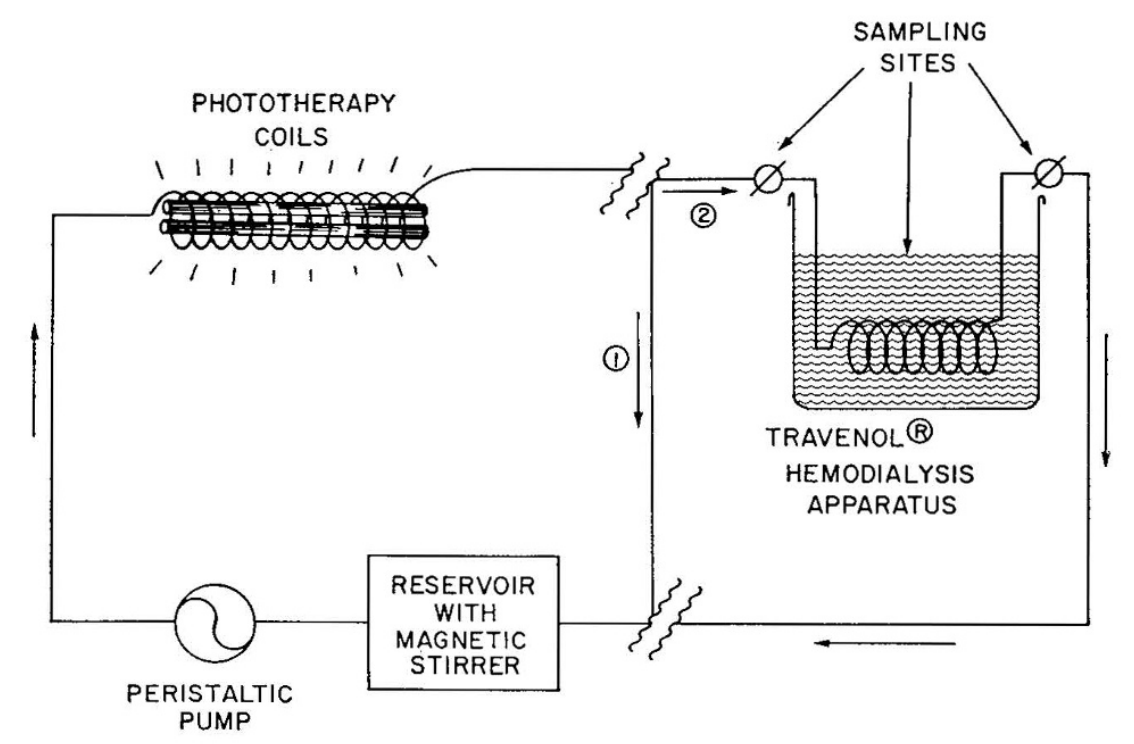

Fig. 3. Experimental design for in vitro phototherapy studies. Phototherapy unit consisted of five standard blood-warming coils connected in series around two blue fluorescent lamps. Long term (24 hr) phototherapy was performed on 350-500-ml aliquots of plasma circulated through pathway 1 . A shorter $(2.5 \mathrm{hr})$ study, in which $3,500 \mathrm{ml}$ plasma were circulated through an artificial kidney in series with the phototherapy coil, employed pathway 2.

the first $24 \mathrm{hr}$ after the intravenous injection of 1-ml plasma samples into Sprague-Dawley and jaundiced Gunn rats prepared with external biliary fistulas and urethral catheters.

In one study, in order to simulate more closely the conditions which would exist during a human extracorporeal phototherapy situation, and to further examine the protein binding and dialyzability of the photodegradation products, the following modifications of the above procedure were employed. (1) The "venous" outflow from the phototherapy coils was passed through a Travenol 100-liter recirculating artificial kidney, employing a Travenol Ultra-Flow $14 \mathrm{~S}$ twin dialysis coil, before its return to the reservoir [79]. For this study, a total of $3,500 \mathrm{ml}$ plasma, obtained from $M E H$ during exchange plasmapheresis, and labeled with $0.5 \mu \mathrm{Ci}$ unconjugated $\left({ }^{3} \mathrm{H}\right)$ bilirubin, was circulated through the system using a peristaltic pump. In order to simulate flows which might be expected from a human arteriovenous shunt, plasma flow rate was maintained at $80-90 \mathrm{ml} / \mathrm{min}$ for the $1 \mathrm{st}$ $\mathrm{hr}$ of the experiment, and $20-30 \mathrm{ml} / \mathrm{min}$ for the $2 \mathrm{nd}$ hr. "Venous pressure" was maintained at 20-30 mm $\mathrm{Hg}$ at all times. Plasma samples were obtained at 10 min intervals from both "arterial" and "venous" sides of the kidney dialysis coil and from the dialysis bath fluid and were analyzed as indicated under 1 and 2 in the paragraph above. Results were used to determine the rate of bilirubin breakdown in the system, as well as the clearance of radioactive photodecomposition products from the plasma by the Travenol artificial kidney.

\section{Results}

\section{In Vivo Studies}

The disappearance curve for radiobilirubin in plasma obtained during the patient's 1971 NIH admission is presented in Figure 4, which also contains corresponding values for bilirubin concentration in plasma. The radiobilirubin curve is similar to those reported previously in patients with $\mathrm{CNJ}$, and shows a rapid curvilinear decline in radiobilirubin content in plasma for the 1st day, followed by a slow exponential disappearance $[11,17,23,62]$. Extrapolation of the exponential portion of the curve to zero time results in a calculated whole body distribution volume for bilirubin of 6,732 ml, a total exchangeable bilirubin pool of $1,746 \mathrm{mg}$, and a daily bilirubin turnover of $3.0 \mathrm{mg} / \mathrm{kg} /$ $24 \mathrm{hr}$. The value for bilirubin turnover is well within the normal range of $3.89 \pm 0.65 \mathrm{mg} / \mathrm{kg} / 24 \mathrm{hr}$ (mean \pm so) determined for normal adults [9], and results in a normal calculated mean erythrocyte lifespan of 101 days, as estimated by the method of Berk et al. [7]. As noted previously, the $\mathrm{t}_{1 / 2}$ of ${ }^{51} \mathrm{Cr}$-labeled erythrocytes was normal also. 


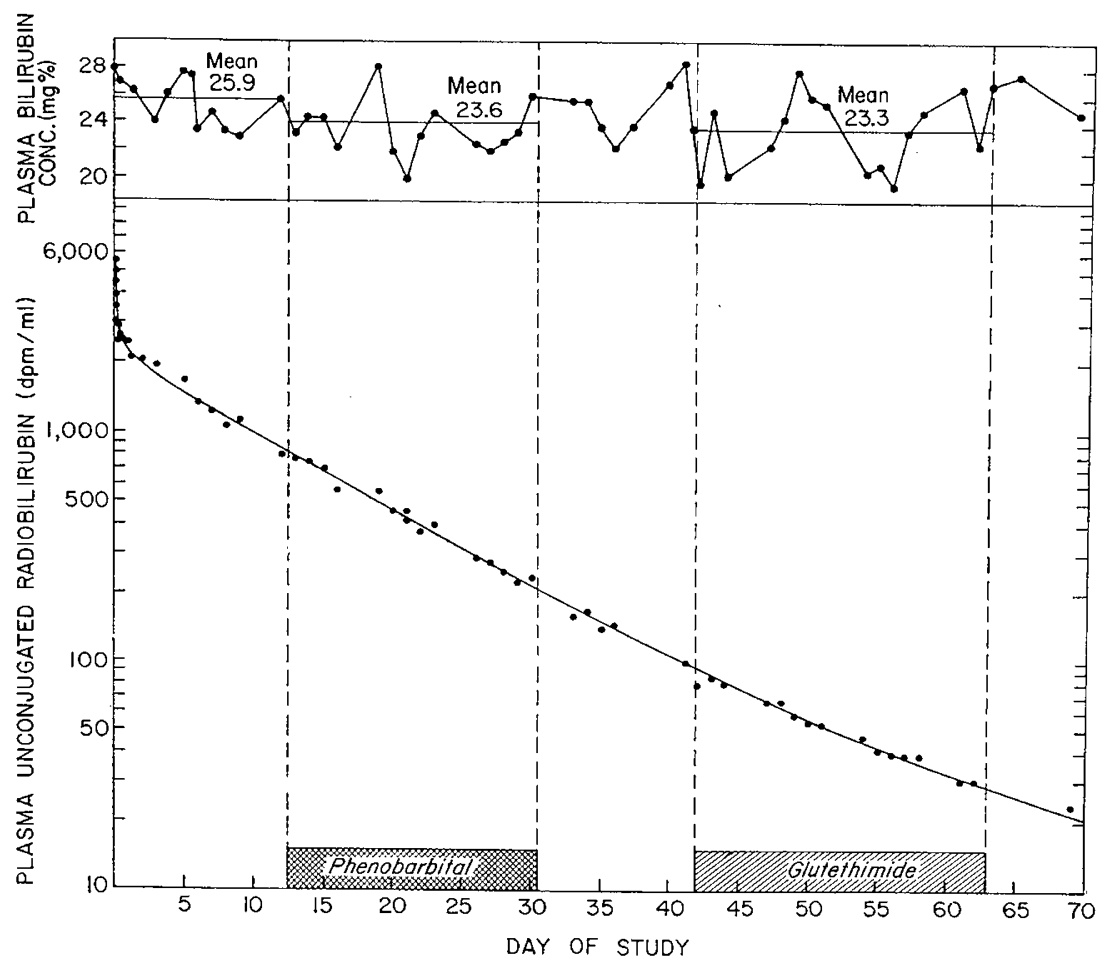

Fig. 4. Plasma radiobilirubin disappearance curve and mean daily bilirubin concentration in $M E H$ during the 1971 study. Neither phenobarbital nor glutethimide reduced the bilirubin concentration in plasma or shortened the radiobilirubin $t_{1 / 2}$.

During the control period, the bilirubin concentration in plasma averaged $25.9 \pm 2.5 \mathrm{mg} / 100 \mathrm{ml}$ (mean $\pm \mathrm{SD}$ ) and was not significantly reduced by the administration of either phenobarbital $(23.6 \pm 2.2 \mathrm{mg} / 100$ $\mathrm{ml}$; Student $t$ test, $P>0.4)$ or glutethimide $(23.3 \pm 2.9$ $\mathrm{mg} / 100 \mathrm{ml} ; P>0.5)$. That the failure of these agents to lower the bilirubin concentration in plasma is caused by a lack of effect on hepatic bilirubin metabolism, and is not merely an artifact which results from mobilization of the enormous tissue stores of bilirubin (see below), is indicated by the failure of both agents to accelerate the rate of radiobilirubin disappearance in plasma (Fig. 4). Although precise calculations of the effects of drug administration on bilirubin turnover cannot be made from these data without a number of further assumptions, the lack of effect on either bilirubin concentration in plasma or radiobilirubin half-life strongly suggests that bilirubin turnover was not increased by drug administration. This is consistent with previous observations in both CNJ $[17,23]$ and Gunn rats [58], which constitute an animal model of this condition.

Data for radiobilirubin in plasma during the 1971 control period were subject to more detailed computer analysis $[9,17]$, the results of which are summarized in
Table I. Analysis of 1971 plasma radiobilirubin disappearance data $^{1}$

\begin{tabular}{llll}
\hline & MEH & \multicolumn{1}{c}{$\begin{array}{c}\text { Normal } \\
\text { control subjects } \\
(\mathrm{n}=24)\end{array}$} & $\begin{array}{c}\text { Gilbert's } \\
\text { syndrome } \\
(\mathrm{n}=36)\end{array}$ \\
\hline $\mathrm{C}_{\mathrm{BR}}(\mathrm{ml} / \mathrm{min} / \mathrm{kg})$ & 0.0075 & $0.65 \pm 0.18^{2}$ & $0.19 \pm 0.07$ \\
$\lambda_{21}\left(\mathrm{~min}^{-1}\right)$ & 0.017 & $0.021 \pm 0.004$ & $0.010 \pm 0.003$ \\
$\lambda_{12}\left(\mathrm{~min}^{-1}\right)$ & 0.013 & $0.005 \pm 0.003$ & $0.009 \pm 0.004$ \\
$\lambda_{02}\left(\mathrm{~min}^{-1}\right)$ & 0.00013 & $0.008 \pm 0.002$ & $0.006 \pm 0.002$ \\
$\mathrm{~S}(\mathrm{mg} / \mathrm{mg} / 100$ & 0.55 & $0.69 \pm 0.27$ & $0.35 \pm 0.14$ \\
$\quad \mathrm{ml} / \mathrm{kg})$ & & & \\
\hline
\end{tabular}

${ }^{1} \mathrm{C}_{\mathrm{BR}}$ : hepatic bilirubin clearance, the volume of plasma from which bilirubin is irreversibly cleared per unit time; $\mathrm{S}$ : relative hepatic bilirubin storage capacity, in milligrams stored per milligrams per $100 \mathrm{ml}$ bilirubin concentration in plasma per kilogram body weight. In a model of unconjugated bilirubin metabolism compartments represented schematically as:

extrahepatic-extravascular $\leftrightharpoons$ plasma $\frac{\lambda_{21}}{\lambda_{12}}$ liver $\stackrel{\lambda_{02}}{\longrightarrow}$ bile.

$\lambda_{21}$ : fractional transfer rate of unconjugated bilirubin (FTR) from plasma pool to hepatic pool; $\lambda_{12}$ : FTR from hepatic pool back to plasma; $\lambda_{02}:$ FTR from hepatic pool to bile.

${ }^{2}$ Mean $\pm \mathrm{SD}$.

Table I. The data provide insight into several aspects of hepatic physiology in CNJ. The following points are of particular interest. Although the fractional rate 
of removal of bilirubin from the liver via the conjugating pathway $\left(\lambda_{02}\right)$ appears to be markedly reduced in $\mathrm{CNJ}$, both hepatic bilirubin uptake $\left(\lambda_{21}\right)$ and storage are within the normal range [9] in this syndrome. In contrast, both hepatic bilirubin uptake [8] and storage [5] are reduced in Gilbert's syndrome, when calculated by similar kinetic analysis. These data indicate that the rate of initial entry of bilirubin into the liver is independent of the subsequent fate of the molecule. In the current patient with $\mathrm{CNJ}$, hepatic bilirubin uptake (calculated as $\lambda_{21} \times$ plasma unconjugated bilirubin pool) was $10,700 \mu \mathrm{g} / \mathrm{min}$, compared with an average normal value of $230 \mu \mathrm{g} / \mathrm{min}$, which illustrates the enormous capacity of the as yet undefined hepatic mechanism for bilirubin uptake.

Measurements of endogenous carbon monoxide production during 1971 were $7.0 \mu \mathrm{M} / \mathrm{kg} / 24 \mathrm{hr}$ during the control period and $10.0 \mu \mathrm{M} / \mathrm{kg} / 24 \mathrm{hr}$ and $6.3 \mu \mathrm{M} / \mathrm{kg} /$ $24 \mathrm{hr}$ during periods of phenobarbital and glutethimide administration, respectively. Both the control and glutethimide values are well within the normal range [10], and do not differ from each other by more than the cumulative error of the method. Although CO production during phenobarbital administration was increased appreciably above control and glutethimide values, we hesitate to attribute this to increased heme catabolism resulting from drug therapy, in view of the lack of effect of phenobarbital on $\mathrm{CO}$ production in 30 other individuals studied in our department [15]. Caloric restriction has been shown recently to augment $\mathrm{CO}$ production [25, 39], and appreciably greater $\mathrm{CO}$ production has been noted in women studied in the premenstrual half of the cycle than in the postmenstrual period [40]. It is possible that the decreased food intake which occurred in our patient during phenobarbital administration as a result of persistent sedation may have augmented $\mathrm{CO}$ production at this time. We were unable, retrospectively, to correlate the measurements of $\mathrm{CO}$ production with the phase of the patient's menstrual cycle.

During the initial 11 days of her second (1972) radiobilirubin study, the bilirubin concentration in plasma averaged $27.7 \pm 1.6 \mathrm{mg} / 100 \mathrm{ml}$, the half-life was 5.4 days, and the bilirubin turnover was $5.1 \mathrm{mg} / \mathrm{kg} / 24 \mathrm{hr}$. The patient had been receiving diphenylhydantoin therapy for a month at the time of this study, so that the changes observed in bilirubin turnover and radiobilirubin half-life, when compared with the 1971 control period, could conceivably be attributable to treatment. Considering the lack of effect of phenobarbital and glutethimide on bilirubin metabolism in this and similar patients with type I CNJ $[1,17,28,34]$, and the specific failure of diphenylhydantoin to alter radiobilirubin clearance in another case [17], this interpretation seems unlikely. In view of the spontaneous fluctuations from $20-35 \mathrm{mg} / 100 \mathrm{ml}$ observed in $M E H$ 's bilirubin concentration in plasma over the years, it is possible that the changes in bilirubin turnover and radiobilirubin $t_{1 / 2}$ also represent random fluctuations attributable to unrecognized physiologic variables.

At the completion of the 11-day 1972 control period, the patient was begun on phototherapy (Fig. 2). Over the subsequent 14 days, the bilirubin concentration in plasma averaged $24.8 \pm 2.0 \mathrm{mg} / 100 \mathrm{ml}$, and the radiobilirubin $t_{1 / 2}$ was 6.5 days. Addition of oral agar to the phototherapy regimen produced no decrease in the radiobilirubin $t_{1 / 2}$, and the bilirubin concentration during combined agar and phototherapy was $25.7 \pm$ $1.2 \mathrm{mg} / 100 \mathrm{ml}$. Thus, neither phototherapy nor agar produced a clinically significant effect on bilirubin concentration or radiobilirubin elimination. The occasional failure of phototherapy to reduce the bilirubin concentration in jaundiced Gunn rats has been shown to be associated with a shortened $t_{1 / 2}$ for radiolabeled bilirubin and has thus been attributed either to an increase in bilirubin production or to the mobilization of extravascular stores [46]. Clearly, no such mechanisms can be invoked in our patient, since the $t_{1 / 2}$ of radiobilirubin during the 1972 study was not shortened by phototherapy.

In contrast to the lack of effect of phototherapy on bilirubin circulating in the plasma, those areas of skin exposed to phototherapy gradually changed from intense yellow-orange to bronze in color, while protected areas remained unchanged. Simultaneously, although there was no apparent change in the color of freshly voided urine, the optical density of the urine pentdyopent reaction mixture increased to $225 \%$ of control values [56]. Although this reaction is only semiquantitative, this suggests that the excretion of photodegradation products of bilirubin in urine, presumably derived from tissue-bound bilirubin in the skin, increased during phototherapy. The apparent lack of effect of phototherapy on plasma bilirubin in $M E H$ may reffect the thicker skin and smaller surface area to plasma volume ratio found in the adult, as compared with the neonate. On the other hand, the $\mathrm{t}_{1 / 2}$ of ${ }^{51} \mathrm{Cr}$. labeled erythrocyte during the first 3 weeks of phototherapy was only 20.2 days, compared with a value of 26.4 days in 1971, which suggests the possibility that sufficient illumination reached the circulation to cause mild erythrocyte injury. Alternatively, photodegrada- 
tion products derived from tissue-bound bilirubin in the skin may have been toxic to erythrocytes. These explanations are clearly speculative, as the observation that bilirubin turnover was increased to $5.1 \mathrm{mg} / \mathrm{kg} / 24$ hr during the 1972 control period suggests that increased erythrocyte destruction, possibly as a sequal to the episode of Klebsiella sepsis, may have been occurring before institution of phototherapy.

Results of analyses of BSP and indocyanine green disappearance curves performed during the 1971 admission are presented in Table II. The plasma BSP disappearance curves took the usual form of a sum of two exponentials [6]. During the control BSP study, the initial disappearance rate from the plasma was normal $\left(\mathrm{t}_{1 / 2}=5.3 \mathrm{~min}\right)$, but abnormal 45 -min BSP retention resulted from the early appearance of a slower than normal second component (Table II). As a result, net $\mathrm{BSP}$ clearance was reduced to $2.4 \mathrm{ml} / \mathrm{min} /$ $\mathrm{kg}$. During drug administration, the BSP disappearance rate in plasma increased somewhat $\left(t_{1 / 2}=3.92\right.$ min for phenobarbital and 3.69 min for glutethimide), presumably reflecting accelerated hepatic uptake of the dye [6]; however, the early appearance of the slow second component continued to result in mildly abnormal 45-min BSP retention and borderline values for BSP clearance. Although 45-min BSP retention has been reported generally as normal in CNJ [4, 17, 24, $33,62]$, values in excess of $5 \%$ have been reported in several cases $[1,63,59]$. The mechanism responsible for the mild abnormalities observed in BSP kinetics in $M E H$ are unclear. The pattern of the curves and the abnormalities in compartmental variables are similar

Table II. Studies of Sulfobromophthalein (BSP) and indocyanine green (ICG) kinetics ${ }^{1}$ in $M E H$

\begin{tabular}{|c|c|c|c|c|}
\hline & Control & $\begin{array}{l}\text { Pheno- } \\
\text { barbital }\end{array}$ & $\begin{array}{l}\text { Glutethi- } \\
\text { mide }\end{array}$ & $\begin{array}{l}\text { Normal control } \\
\text { subjects } \\
(\mathrm{n}=12)\end{array}$ \\
\hline \multicolumn{5}{|l|}{ BSP study } \\
\hline $\mathrm{A}$ & 0.84 & 0.92 & 0.89 & $0.95 \pm 0.06^{2}$ \\
\hline B & 0.16 & 0.08 & 0.11 & $0.05 \pm 0.06$ \\
\hline $\mathrm{k}_{1}\left(\min ^{-1}\right)$ & 0.15 & 0.19 & 0.21 & $0.14 \pm 0.02$ \\
\hline $\mathrm{k}_{2}\left(\min ^{-1}\right)$ & 0.016 & 0.015 & 0.012 & $0.033 \pm 0.018$ \\
\hline Initial PDR ${ }^{3}\left(\min ^{-1}\right)$ & 0.13 & 0.18 & 0.19 & $0.14 \pm 0.02$ \\
\hline $\begin{array}{l}\text { 45-Min BSP retention } \\
(\%)\end{array}$ & 10.8 & 6.7 & 9.4 & $\leq 5.0$ \\
\hline $\mathrm{C}_{\mathrm{BSP}^{5}}(\mathrm{ml} / \mathrm{min} / \mathrm{kg})$ & 2.4 & 3.5 & 2.7 & \pm 0.7 \\
\hline \multicolumn{5}{|l|}{ ICG study } \\
\hline $\mathrm{CrCG}^{5}(\mathrm{ml} / \mathrm{min} / \mathrm{kg})$ & 11.0 & 15.6 & 12.7 & \pm 1.6 \\
\hline
\end{tabular}

${ }^{1} \mathrm{BSP}$ curve was fitted to the function BSP $(\mathrm{t}) / \mathrm{BSP}_{0}=\mathrm{Ae}^{-\mathrm{k}_{1} \mathrm{t}}+\mathrm{Be}^{-\mathrm{k}_{2} \mathrm{t}}$. 2. Mean \pm so.

${ }^{3}$ Initial plasma disappearance rate represents the derivative of the function [BSP $(\mathrm{t}) / \mathrm{BSP}_{0}$ ] at zero time. The initial $\mathrm{t}_{1 / 2}$ of $\mathrm{BSP}$ is determined as $\mathrm{t}_{1 / 2}=0.693$ / PDR.

4 Plasma BSP concentration at $45 \mathrm{~min} \times 10$.

5 Volumes of plasma irreversibly cleared of BSP or ICG per unit time, calculated as described previously [6].
Table $I I I$. Studies of salicylamide metabolism in $M E H^{1}$

\begin{tabular}{lccccr}
\hline \multicolumn{1}{c}{ Study } & SG & SS & GG & Total & $\mathrm{t}_{1 / 2^{2}, \min }$ \\
\hline$M E H$ control & 31 & 237 & 78 & 346 & $>360$ \\
$M E H$ phenobarbital & 64 & 250 & 215 & 530 & 226 \\
$M E H$ glutethimide & 59 & 282 & 239 & 580 & 207 \\
Normal control sub- & $548 \pm$ & $235 \pm$ & $135 \pm$ & $917 \pm$ & $73 \pm$ \\
jects $(\mathrm{n}=15)^{3}$ & 32 & 44 & 24 & 31 & 6 \\
\hline
\end{tabular}

1 Values are represented in milligrams. SG: salicylamide glucuronide; SS: sali cylamide sulfate; GG: gentisamide glucuronide; Total: total metabolites recovered in urine during the $4 \mathrm{hr}$ following an oral dose of $1.0 \mathrm{~g}$ salicylamide. Normal control values are from Song et al. [64].

${ }^{2}$ Time for $50 \%$ of administered salicylamide to be excreted in the urine.

${ }^{3}$ Mean $\pm \mathrm{sD}$.

to those observed in some patients with Gilbert's syndrome (Reference 6, group 2).

Indocyanine green (ICG) clearance in $M E H$ was normal $(11.04 \mathrm{ml} / \mathrm{min} / \mathrm{kg})$ during the control study, and increased somewhat during drug therapy. There was a high degree of correlation between the three pairs of values for $\mathrm{C}_{B S P}$ and $\mathrm{C}_{Y C G}$ obtained under baseline conditions and during drug administration $(\mathrm{r}=$ $0.99)$.

Studies of salicylamide metabolism are presented in Table III. During the baseline period, 4-hour excretion of salicylamide glucuronide and gentisamide glucuronide in urine were reduced to $6 \%$ and $58 \%$, respectively, of normal, whereas sulfate conjugation was within the normal range. Administration of either phenobarbital or glutethimide increased the metabolism of salicylamide to gentisamide glucuronide to values which exceeded the normal range. Excretion of salicylamide glucuronide doubled during drug administration, but was still markedly reduced. There was also a small increase in excretion of salicylamide sulfate during therapy. Although decreased conversion of salicylamide to its glucuronide metobolites has been reported in CNJ [4], the finding of normal sulfate conjugation, although not unexpected, has not been documented previously.

An assay of hepatic bilirubin UDP-glucuronyl transferase, performed on a needle biopsy specimen in March 1972, failed to demonstrate any bilirubin conjugation, despite the administration of enzyme-inducing antiepileptic agents for more than 1 month before the biopsy.

\section{In Vitro Phototherapy Studies}

Results of typical in vitro phototherapy studies are illustrated in Figure 5. A study involving $24 \mathrm{hr}$ of continuous recirculation and illumination of a $500-\mathrm{ml}$ aliquot of $M E H$ 's labeled plasma is presented in Figure $5 A$. A shorter experiment, in which a Travenol artificial kidney was added to the circuit and which in- 


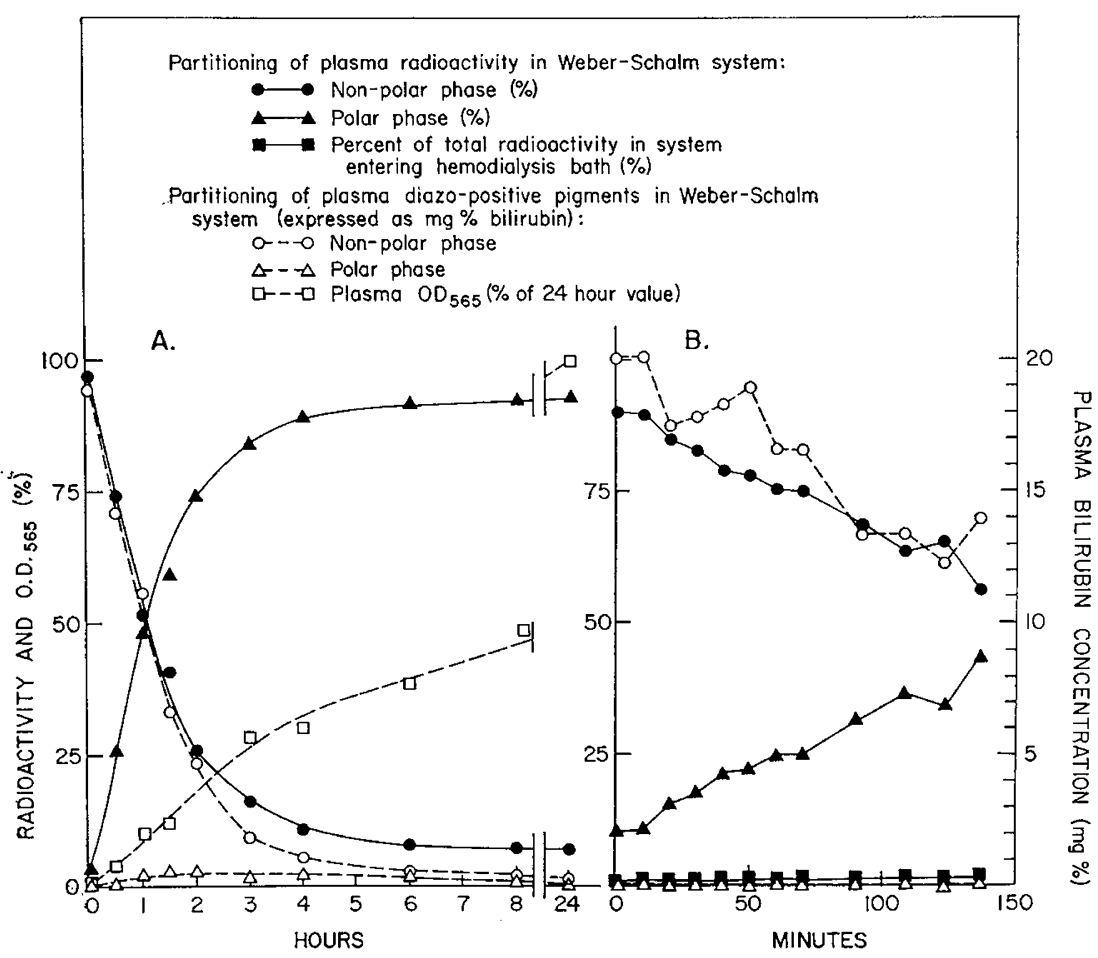

Fig. 5. Results of in vitro phototherapy of $M E H$ 's plasma, labeled with $\left({ }^{14} \mathrm{C}\right)$ bilirubin. $A$ : results of a $24-\mathrm{hr}$ study on a $500-\mathrm{ml}$ plasma aliquot. $B$ : represents a $2.5 \mathrm{hr}$ study, employing $3,500 \mathrm{ml}$ plasma, in which a Travenol artificial kidney was placed in series with the phototherapy coil. Both studies demonstrate rapid degradation of unconjugated bilirubin to polar, diazo-negative products. A new absorption peak at 565 $\mathrm{nm}$ appears more slowly $(A)$, suggesting that photodegradation of bilirubin may involve more than one step. Photodegradation products formed during the initial $150 \mathrm{~min}$ are not dialyzable by the artificial kidney $(B)$.

volved 3,500 ml plasma, is represented in Figure 5B. As illustrated in these figures, despite the failure of in vivo phototherapy to alter the bilirubin concentration in plasma of the patient, exposure of her plasma to blue light in vitro rapidly degraded the unconjugated bilirubin, which resulted in its conversion to polar, diazo-negative components which partitioned into the upper layer of a Weber-Schalm solvent partition system. The hemodialysis experiment (Fig. $5 B$ ), involving a quantity of plasma equivalent to $M E H$ 's plasma volume, suggested that extracorporeal phototherapy might rapidly degrade the quantities of bilirubin present in her circulation.

In vivo phototherapy has been reported to produce, on occasion, a number of untoward side effects, including diarrhea [38], hemolysis [14, 36, 44], and, at least in rats, cholestasis [47]. Because we were, accordingly, reluctant to expose the patient to the large quantities of photodegradation products of unknown structure and uncertain toxicity that would very rapidly be produced by the extracorporeal illumination of her plasma, we attempted to remove the degradation products by both conventional dialysis experiments and with the use of an artificial kidney (Fig. $5 B$ ). Previous reports had suggested that the photodegradation products were small, highly polar, water-soluble materials which were excreted at least partially in the urine [19, 46]. These characteristics suggested a relatively low order of protein binding $[16,50]$. Nevertheless, we found that $(I)$ products formed during the initial 150 min of phototherapy were virtually nondialyzable by the artificial kidney (Fig. 5B); (2) over the course of 24 hr of in vitro phototherapy there was a gradual increase in the percentage of radioactive photodegradation products which were dialyzable through cellophane membranes into phosphate buffer (Table IV), but at all times, an appreciable proportion of the radioactivity was nondialyzable. In these dialysis experiments, 7 days were required to achieve equilibrium, perhaps explaining the greater recovery in this study than in the hemodialysis experiment. (3) Predominant binding of the nondialyzable photodegradation products to albumin was indicated by their retention on albumin-conjugated agarose columns, and elution only under conditions (e.g., 50\% ethanol) similar to those required to elute such albumin-bound organic 
Table IV. Albumin binding of photodegradation products of bilirubin [80]

\begin{tabular}{|c|c|c|c|c|c|c|}
\hline \multirow{2}{*}{ Variable } & \multicolumn{6}{|c|}{ Period of illumination, min } \\
\hline & 0 & 60 & 180 & 360 & 480 & 1440 \\
\hline $\begin{array}{l}\text { A. Radioactivity in plasma as unconjugated } \\
\text { bilirubin }(\%)^{1}\end{array}$ & 100.0 & 59.4 & 10.1 & 2.9 & 2.1 & 0.6 \\
\hline $\begin{array}{l}\text { B. Radioactivity in plasma as photodegra- } \\
\text { dation products }(\%)^{2}\end{array}$ & & 40.6 & 89.9 & 97.1 & 97.9 & 99.4 \\
\hline $\begin{array}{c}\text { C. Radioactivity which bound to columns } \\
\text { (\% of total plasma radioactivity) }\end{array}$ & $90.3^{3}$ & 82.0 & 69.3 & 65.1 & 60.6 & 32.6 \\
\hline $\begin{array}{l}\text { D. Radioactivity bound to columns as un- } \\
\text { conjugated bilirubin (\% of total } \\
\text { plasma radioactivity })^{3}\end{array}$ & 90.3 & 53.6 & 9.1 & 2.6 & 1.9 & 0.5 \\
\hline $\begin{array}{l}\text { E. Radioactivity bound to columns as pho- } \\
\text { todegradation products ( } \% \text { of total } \\
\text { plasma radioactivity })^{4}\end{array}$ & & 28.4 & 60.2 & 62.5 & 58.7 & 32.1 \\
\hline $\begin{array}{l}\text { F. Porportion of photodegradation products } \\
\text { in plasma which bound to column } \\
(\%)^{5}\end{array}$ & & 70.0 & 67.0 & 64.4 & 60.0 & 32.3 \\
\hline $\begin{array}{l}\text { G. Proportion of photodegradation products } \\
\text { in plasma which did not bind to col- } \\
\text { umn }(\%)\end{array}$ & & 30.0 & 30.3 & 35.6 & 40.0 & 67.7 \\
\hline $\begin{array}{l}\text { H. Proportion of bound counts representing } \\
\text { photodegradation products }{ }^{6}\end{array}$ & & 34.6 & & 96.2 & & 98.5 \\
\hline $\begin{array}{l}\text { I. Percentage of bound counts eluted with } \\
\qquad 1 \mathrm{~m} \mathrm{NaCl}\end{array}$ & & 0.5 & & 2.7 & & 7.3 \\
\hline Color of saline eluate & Clear & Clear & & Clear & & Clear \\
\hline $\begin{array}{l}\text { J. Percentage of photodegradation products } \\
\text { eluted with } 1 \mathrm{M} \mathrm{NaCl}^{7}\end{array}$ & & 1.4 & & 2.8 & & 7.4 \\
\hline $\begin{array}{l}\text { K. Percentage of bound counts eluted with } \\
50 \% \mathrm{EtOH}\end{array}$ & 96.0 & 98.0 & & 107.0 & & 96.4 \\
\hline L. Recovery of bound counts ${ }^{8}$ & 96.0 & 98.5 & & 109.7 & & 103.7 \\
\hline Color of ethanol eluate & Yellow & $\begin{array}{r}\text { Yellow, } \\
\text { green }\end{array}$ & & $\begin{array}{l}\text { Discrete yellow, green, } \\
\text { and violet bands }\end{array}$ & & $\begin{array}{l}\text { Discrete yellow and } \\
\text { violet bands }\end{array}$ \\
\hline $\begin{array}{l}\text { M. Percentage of photodegradation products } \\
\text { dialyzable through cellophane mem- } \\
\text { branes in } 7 \text { days }^{9}\end{array}$ & & 24.1 & 23.6 & 24.6 & 27.5 & 38.0 \\
\hline
\end{tabular}

\footnotetext{
${ }^{1}$ The percentage of radioactivity in plasma as unconjugated bilirubin was taken to be the same as the plasma bilirubin concentration (diazo reaction) expressed as percentage of the initial value.

${ }^{2} \mathrm{~B}=100-\mathrm{A}$.

${ }^{3}$ When $1 \mathrm{ml}$ plasma containing a range of $\left({ }^{14} \mathrm{C}\right)$ bilirubin concentrations up to $20.0 \mathrm{mg} / 100 \mathrm{ml}$ was added to these columns, a highly reproducible proportion (average $90.3 \%$ ) bound, as determined by both radioactivity and chemical measurements. Accordingly, D was calculated as $0.903 \times \mathrm{A}$.

${ }^{4} \mathrm{E}=\mathrm{C}-\mathrm{D}$.

${ }^{5} \mathrm{~F}=\mathrm{E} \div \mathrm{B}$.

${ }^{6} \mathrm{H}=\mathrm{E} \div \mathrm{C}$.

${ }^{7} \mathrm{~J}=\mathrm{I} \div \mathrm{H}$.

${ }^{8} \mathrm{~L}=\mathrm{K}+\mathrm{I}$.

${ }^{9} \mathrm{M}=$ Percentage of total counts in dialysis bath $\div$ B.
}

anions as unconjugated bilirubin, BSP, and indocyanine green (Table IV) [53]. The proportion of photodegradation products retained on the columns decreased as the duration of illumination increased, in keeping with the results of the dialysis experiments. There was a high degree of correlation $(\mathrm{r}=0.99)$ between the proportion of the photodegradation products which were dialyzable and the proportion which did not bind to the albumin-agarose columns (Table IV).
Photodegradation products produced over the initial $8 \mathrm{hr}$ of illumination were excreted predominantly in the bile of both Sprague-Dawley and jaundiced Gunn rats, as would be expected for a low molecular weight organic anion which was tightly albumin bound. In contrast, the pigments present after $24 \mathrm{hr}$ of illumination, which were less tightly protein bound in both the dialysis and affinity chromatography studies, were excreted predominantly in the urine. When 1-ml ali- 
quots of $M E H$ 's plasma, illuminated for varying periods of time during the experiment illustrated in Figure $5 \mathrm{~A}$, were injected intravenously into bile fistula Sprague Dawley rats, the proportion of the recovered breakdown products excreted in the urine over the subsequent 24-48 hr increased progressively from $0 \%$ in the $60-\mathrm{min}$ sample to an average of $62.4 \%$ in samples illuminated for $24 \mathrm{hr}$. There was a corresponding fall in the proportion of such products recovered in bile from $100 \%$ to $37.6 \%$. A similar, but less precisely defined trend appeared to be occurring when analogous samples were injected into jaundiced Gunn rats with external biliary fistulae. Maximum recovery of injected photodegradation products in urine, $42.4 \%$, again occurred in the sample illuminated for $24 \mathrm{hr}$.

During the course of $24 \mathrm{hr}$ of phototherapy, the appearance and progressive augmentation of a small new absorption peak at $565 \mathrm{~nm}$ occurred more slowly than the conversion of bilirubin to polar, diazo-negative materials which partitioned into the upper layer of the Weber-Schalm solvent system (Fig. $5 A$ ). With continued illumination the plasma turned from yellow to green to brown to almost black. Affinity chromatography of plasma samples obtained after varying periods of illumination, using albumin-conjugated agarose columns, resulted in the isolation of predominantly yellow and green pigments in early samples, whereas both a nonbilirubin yellow pigment and an intensely purple band were isolated from a sample illuminated for 24 hr (Table IV). There was also a gradual increase in the proportion of colorless degradation products which bound weakly to the agarose-albumin columns and could be eluted with $1 \mathrm{M} \mathrm{NaCl}$ (Table IV). These observations, as well as the data on dialyzability and biliary excretion of photodegradation products presented above, indicate that the photocatabolism of bilirubin occurs in a number of distinct steps and results in the production of a variety of products, as has been previously proposed $[47,48]$. Our observations on both protein binding and routes of excretion of bilirubin photodegradation products confirm and amplify the earlier studies of Ostrow and coworkers $[45,51]$. These data also suggest that affinity chromatography on agarose-albumin columns may provide an efficient means of isolating individual photodegradation products of bilirubin as an aid to their ultimate structural elucidation.

Although photodegradation of albumin in the illuminated plasma samples, as suggested by Odell et al. [43], cannot be ruled out as an alternative explanation for the apparent decrease in protein binding observed with prolonged illumination, it is unlikely to explain the results of the rat studies. Even if the illuminated plasma, injected into the animals, contained predominantly degraded albumin, photodegradation products with a high protein affinity should have bound after injection to the un-illuminated rat albumin and have been excreted in the bile. This is the predominant route of excretion, in the rat, of photodegradation products produced by both in vivo and short term in vitro phototherapy [46-48].

\section{Discussion}

In 1952 Crigler and Najjar [24] described six infants in three related families in whom severe jaundice, with bilirubin concentrations in plasma of $26-45 \mathrm{mg} / 100$ $\mathrm{ml}$, appeared within the first 3 days after birth and persisted throughout life. The bilirubin in plasma was virtually all indirect reacting, and there was no bilirubinuria; there was no evidence of either hemolysis or blood group incompatibilities; and although both hepatic architecture and conventional liver function tests including BSP clearance were normal, bilirubin loading studies, performed in two of the original patients, indicated an abnormality of hepatic bilirubin metabolism. It was shown subsequently that this abnormality resulted from the autosomally recessive inheritance of a complete absence of the conjugating enzyme bilirubin UDP-glucuronyltransferase [1, 2, 21, 52, 63, 67].

In addition to the six patients who were the basis of the original report, a seventh related infant had died at age 26 days with severe jaundice, and examination of family records covering six generations suggested the occurrence of 15 additional cases. Three additional patients have subsequently been born in the same kindred, of whom two, $M E H$ and her affected brother, are included in the pedigree shown in Figure 1, while the third is currently alive and well under the care of Dr. Gerard B. Odell at Johns Hopkins [55]. Patient $M E H$ has been described previously [20, 21].

Since the first report by Crigler and Najjar, more than 40 additional publications, from eastern and western Europe, Egypt, Israel, India, Pakistan, and South America, have described similar cases. Two cases have been reported in Negro infants [17, 71]. Useful bibliographies, listing cases to 1969, may be found in the reviews of Kaplan et al. [33] and Bartolozzi et al. [4]. The number of patients reported is now in excess of 60 , with more than 25 additional probable cases being recorded among relatives. Although satisfactory documentation of the biochemical defect was lacking in many of these reports, the clinical picture, in associa- 
tion with a documented history of consanguinity or familial occurrence of multiple infants with kernicterus strongly supports the diagnosis in most instances. In several instances, data are insufficient to distinguish between the Crigler-Najjar syndrome, now designated as $\mathrm{CNJ}$ type $I$, and the phenotypically similar but dominantly inherited syndrome (CNJ type II) described subsequently by Arias [1], in which there appears to be only partial glucuronyltransferase deficiency. In this category must be included the thoroughly evaluated case reported by Micheli and Dominici in 1932 [42], 20 years before the report of Crigler and Najjar [24].

Of the seven patients described in the original report of CNJ [24], six developed a neurologic syndrome shortly after birth which resembled kernicterus, resulting in death by the age of 15 months. This has been the typical natural history of this condition. In contrast, one of the original patients, $J D H$, a double first cousin of $M E H$, developed normally into his teens, with no detectable neurologic damage despite persistent indirect-reacting hyperbilirubinemia in excess of $20 \mathrm{mg} / 100 \mathrm{ml}$. This patient suddenly developed a neurologic syndrome similar to kernicterus, without any apparent precipitating event, at age 16. Neurologic deterioration was rapid and progressive, leading to death within 6 months $[18,27]$. A similar but unrelated child first developed brain damage at age 3, again without known precipitating cause [59]. In the case reported by Bloomer et al. [17], catastrophic neurologic damage occurred in association with a febrile illness at age 9 months in an infant whose development had been normal to that time. The development of brain damage in $M E H$, at age 18, merely serves to re-emphasize that the risk of disabling or fatal bilirubin encephalopathy in these patients is not restricted to the neonatal period, and that vigorous efforts to reduce the bilirubin concentration in plasma appear to offer the only hope of normal survival to afflicted individuals.

The factors precipitating the late onset of neurologic disease remain unclear. At the time of her second NIH admission, $M E H$ had a bilirubin concentration of $34-36 \mathrm{mg} / 100 \mathrm{ml}$ and an albumin concentration of $3.9 \mathrm{~g} / 100 \mathrm{ml}$, so that her molar bilirubin to albumin ratio was 1.09. Because of a markedly lower binding constant for the addition of the second bilirubin molecule to albumin [32], exceeding the ratio of 1.0 may produce a sudden 300 -fold increase in the plasma concentration of unbound bilirubin, which is believed to be the neurotoxic agent. Although this bilirubin concentration is within the range observed repeatedly in $M E H$ over the years, it is conceivable that a random small increase in bilirubin concentration coincided with a small reduction in albumin levels which pushed the molar bilirubin to albumin ratio above the critical value of 1.00

The onset and early course of neurologic disease in $M E H$ was strikingly similar to that reported in her cousin, $J D H$. In contrast to the rapidly fatal course in the latter instance, there has been no real evidence of further deterioration in $M E H$ for more than a year after the abrupt, if transitory, reduction of her bilirubin concentration in plasma by exchange plasmapheresis. Although we would like to believe that exchange plasmapheresis in some way interrupted the course of neurologic deterioration by lowering both plasma and spinal fluid bilirubin levels at a critical period, hard evidence in support of this hypothesis is lacking.

One interesting piece of physiologic information was obtained from the plasmapheresis experience. The total amount of bilirubin removed in the four exchange plasmaphereses $(1,900 \mathrm{mg})$ was similar to the total "exchangeable" bilirubin pool estimated by isotope dilution during the two radiobilirubin turnover studies (1971: 1,746 mg; 1972: 2,176 mg). Nevertheless, after abrupt removal of this quantity of pigment, the patient was still hyperbilirubinemic, and relatively little immediate change was noted in the deep yelloworange color of her skin. This finding, as well as the discrepancy between the effects of phototherapy on bilirubin in plasma and in the skin, supports the hypothesis that these patients have accumulated very large tissue deposits of bilirubin quantitatively far in excess of the "exchangeable pool." Such deposits, observed at autopsy on a number of occasions [27, 31], may exchange with plasma already saturated with bilirubin too slowly to be reflected in steady state kinetic studies, but may be mobilized readily when plasma is replaced with albumin containing large numbers of available bilirubin binding sites.

We are continuing to explore the possible therapeutic uses of extracorporeal phototherapy. By connecting the IBM/NCI cell separator in series with a phototherapy system, it may be possible to avoid damage to erythrocytes (which was suggested during in vivo phototherapy period), provided that this damage is directly caused by exposure of erythrocytes to light, and not to any toxic effects of the photodegradation products on erythrocytes. Clinical exploitation of extracor- 
poreal phototherapy will ultimately depend on one of two developments: either a clear-cut demonstration that the rapid production of large quantities of photodegradation products is nontoxic, or the availability of a method to remove phototherapy degradation products from the circuit before reinfusion of the treated plasma into the patient. The data which suggest tight binding of these products to albumin indicate a possible approach to solving the latter problem. Extensive studies have demonstrated that albumin-conjugated agarose columns are highly efficient in extracting albumin-bound organic anions from plasma [53]. Hence, a three-step circuit, including an IBM/NCI cell separator, a phototherapy coil, and an albumin-conjugated agarose column, in series, may make it possible to destroy bilirubin in a continuous flow extracorporeal circuit and to remove photodegradation products before reinfusion. Preliminary calculations suggest that once tissue stores of bilirubin are depleted, two or three overnight perfusions per week through such a system could destroy the total weekly bilirubin production and maintain an acceptable bilirubin concentration in plasma, much as twice or thrice weekly hemodialysis suffices for many patients with chronic renal disease. The cost of the IBM/NCI cell separator and the need for a staff of highly trained personnel to operate it would make this system an expensive therapeutic modality.

An alternative, and, at this time, even more speculative approach is suggested by the observation that when jaundiced whole blood (derived from $M E H$ ) is passed over albumin-conjugated agarose columns, there is highly efficient removal of unconjugated bilirubin from the plasma with no apparent damage to any formed blood elements, clotting factors, or other plasma proteins [53]. In preliminary studies perfusion of the blood of Gunn rats over such columns via a carotid-jugular fistula was highly effective in reducing the bilirubin concentration in plasma in these animals [61]. Hence, direct perfusion of blood from patients with $\mathrm{CNJ}$ over similar columns, without the need for an expensive continuous flow centrifuge, may provide a cheaper, but equally effective means of maintaining the bilirubin concentration within acceptable bounds.

The ultimate approach to therapy in CNJ is likely to derive from advances in hepatic transplantation. Rug. stad et al. [60] have shown that a small piece of well differentiated hepatoma implanted into the thigh of Gunn rats will conjugate sufficient bilirubin to appreciably lower the bilirubin levels in plasma, inasmuch as the resulting conjugate is excreted normally by the liver. In patients with CNJ, an auxiliary liver transplant could perform the same service. Auxiliary transplants are particularly appealing in this situation, because they leave intact the patient's own liver, which functions normally in all respects except for the conjugation of bilirubin. Until very recently, both clinical and experimental studies of auxiliary transplantation were extremely discouraging and the procedure had been largely abandoned in man [66]. Recent appreciation of the crucial role of portal blood in the maintenance of such grafts [65] suggests that a re-examination of this approach in the future will be warranted. Indeed, some progress in solving the problem of nonimmunologic graft atrophy which has plagued auxiliary transplantation is suggested by a recent preliminary report of three human auxiliary transplants with survival of up to 9 months [26]. Because of the high incidence of consanguinity and very extensive inbreeding in the pedigrees of patients with type $I \mathrm{CNJ}$, solution of the technical aspects of obtaining the donor graft and its surgical implantation may pose a greater problem than the immunologic aspects of graft rejection in this particular situation. Orthotopic transplantation was considered in $M E H$ at the time of her initial neurologic deterioration, but her apparent response to exchange plasmapheresis and the highly experimental nature of such transplants have encouraged more conservative management. The question is being reviewed periodically in the light of both the patient's clinical condition and current statistics on the results of human hepatic transplantation. It would certainly be strongly considered in the face of further neurologic deterioration which was not reversed by any of the "conservative" measures outlined above.

\section{Summary}

The authors describe a case of Crigler-Najjar syndrome (type I congenital nonhemolytic jaundice) in whom the onset of bilirubin encephalopathy did not occur until 18 years of age. Detailed physiologic studies of bilirubin metabolism, erythrocyte survival, glucuronide formation, and of the effects of phototherapy and enzyme-inducing drugs in this patient are reported.

\section{References and Notes}

1. Arias, I. M., Gartner, L. M., Cohen, M., Ben-Ezzer, J., AND Levr, A. J.: Chronic nonhemolytic unconjugated hyper- 
bilirubinemia with glucuronyl transferase deficiency: Clinical, biochemical, pharmacologic, and genetic evidence for heterogeneity. Amer. J. Med., 47: 395 (1969).

2. Axelrod, J., Schmid, R., and Hammaker, L.: A biochemical lesion in congenital, non-obstructive, non-haemolytic jaundice. Nature, 180: 1426 (1957).

3. Barrett, P. V. D., Mullins, F. X., ANd Berlin, N. I.: Studies on the biosynthetic production of bilirubin- $\mathrm{C}^{14}$ : An improved method utilizing delta-aminolevulinic acid- $-{ }^{-14} \mathrm{C}$ in dogs. $\mathrm{J}$. Lab. Clin. Med., 68: 905 (1966).

4. Bartolozzi, G., Ciampolini, M., Saltr, R., and Verrotry, M.: La malattia di Crigler-Najjar: Presentazione di un caso. Minerva Pediat., 21: 2393 (1969).

5. BERK, P. D.: Unpublished observations.

6. BERK, P. D., BlaschKe, T. F., AND WAGgoner, J. G.: Defective BSP clearance in patients with constitutional hepatic dysfunction (Gilbert's syndrome). Gastroenterology, 63: 472 (1972).

7. Berk, P. D., Bloomer, J. R., Howe, R. B., Blaschie, T. F., AND BERLIN, N. I.: Bilirubin production as a measure of red cell life span. J. Lab. Clin. Med., 79: 364 (1972).

8. Berk, P. D., Bloomer, J. R., Howe, R. B., AND Berlin, N. I.: Constitutional hepatic dysfunction (Gilbert's syndrome): A new definition based on kinetic studies with unconjugated radiobilirubin. Amer. J. Med., 49: 296 (1970).

9. BeRK, P. D., Howe, R. B., Bloomer, J. R., AND BerLin, N. I.: Studies of bilirubin kinetics in normal adults. J. Clin. Invest., 48: 2176 (1969).

10. Berk, P. D., Rodkey, F. L., Blaschie, T. F., Collison, H. A., AND WAGGONER, J. G.: Comparison of plasma bilirubin turnover and carbon monoxide production in man. J. Lab. Clin. Med. 83: 29 (1974).

11. Billing, B. H., Gray, C. H., Kulczycka, A., Manfield, P., AND Nrcholson, D. C.: The metabolism of ${ }^{14} \mathrm{C}$-bilirubin in congenital nonhaemolytic hyperbilirubinaemia. Clin. Sci., 27: 163 (1964).

12. BLACK, M., AND BILling, B. H.: Hepatic bilirubin UDP glucuronyl transferase activity in liver disease and Gilbert's syndrome. New Engl. J. Med., 280: 1266 (1969).

13. BLACK, M., AND SHERLOCK, S.: Treatment of Gilbert's syndrome with phenobarbitone. Lancet, $i: 1359$ (1970).

14. Blackburn, M. G., Orzalesi, M. M., and Pigrom, P.: Effect of light and bilirubin on fetal red blood cells in vitro. Biol. Neonatorum, 21: 35 (1972).

15. Blaschke, T. F., Berk, P. D., Rodkey, F. L., Scharschmidt, B. F., Colluson, H. A., And Waggoner, J. G.: Drugs and the liver. I. Effects of glutethimide and phenobarbital on hepatic bilirubin clearance, plasma bilirubin turnover and carbon monoxide production in man. Biochem. Pharmacol. (in press).

16. Blondheim, S. H., Lathrop, D., and Zabriskie, J.: Effect of light on the absorption spectrum of jaundiced serum. J. Lab. Clin. Med., 60: 31 (1962).

17. Bloomer, J. R., Berk, P. D., Howe, R. B., ANd Berlin, N. I.: Bilirubin metabolism in congenital nonhemolytic jaundice. Pediat. Res., 5: 256 (1971).

18. Blumenschein, S. D., Kallen, R. J., Storey, B., NatzschKa, C., Odell, G. B., and CHILds, B.: Familial nonhemolytic jaundice with late onset of neurological damage. Pediatrics, 42: 786 (1968).

19. Callahan, E. W., Thaler, M., Karon, M., Bauer, K., and SCHMID, R.: Phototherapy of severe unconjugated hyper- bilirubinemia: Formation and removal of labeled bilirubin derivatives. Pediatrics, 46: 841 (1970).

20. Childs, B., and NaJJar, V. A.: Familial nonhemolytic jaundice with kernicterus: A report of two cases without neurologic damage. Pediatrics, 18: 369 (1956).

21. Childs, B., Sidbury, J. B., ANd Mrgeon, C. J.: Glucuronic acid conjugation by patients with familial nonhemolytic jaundice and their relatives. Pediatrics, 23: 903 (1959).

22. Coburn, R. F., Blakemore, W. S., and Forster, R. E.: Endogenous carbon monoxide production in man. J. Clin. Invest., 42: 1172 (1963).

23. CRigler, J. F., JR., ANd Gold, N. I.: Effect of sodium phenobarbital on bilirubin metabolism in an infant with congenital nonhemolytic unconjugated hyperbilirubinemia, and kernicterus. J. Clin. Invest., 48: 42 (1969).

24. Crigler, J. F., JR., and NaJjar, V. A.: Congenital familial nonhemolytic jaundice with kernicterus. Pediatrics, 10: 169 (1952).

25. Egger, G., Kutz, K., Bircher, J., Bachofen, H., and Preisic, R.: Bilirubin production in subjects with Gilbert's syndrome. In: G. Paumgartner and R. Preisig: The Liver: Quantitative Aspects of Structure and Function (S. Karger, Basel, 1973).

26. Fortner, J. G., Kinne, D. W., Kim, D., Castro, E. B., Shiu, M. H., Howland, W. S. Benua, R. S., Yeh, S. D. J., and MonaHAN, W. G.: Human auxiliary liver transplantation (Abstract). Gastroenterology, 64: 728 (1973).

27. Gardner, W. A., AND Konigsmark, B.: Familial nonhemolytic jaundice: bilirubinosis and encephalopathy. Pediatrics, 43: 365 (1969).

28. Gorodischer, R., Levy, G., Krasner, J., and Yaffe, S. J.: Congenital nonobstructive, nonhemolytic jaundice: Effect of phototherapy. New Engl. J. Med., 282: 375 (1970).

29. Graw, R. G., JR., BUCKNer, C. D., AND EIseL, R.: Plasma exchange transfusion for hepatic coma: New technique. Transfusion, 10: 26 (1970).

30. Howe, R. B., Berk, P. D., Bloomer, J. R., ANd Berlin, N. I.: Preparation and properties of specifically labeled radiochemically stable ${ }^{3} \mathrm{H}$-bilirubin. J. Lab. Clin. Med., 75: 499 (1970).

31. Huang, P. W. H., Rozpilsky, B., Gerrard, J. W., Goluboff, N., and Holman, G. H.: Crigler-Najjar syndrome in four of five siblings with post-mortem findings in one. Arch. Pathol., 90: $536(1970)$.

32. JACOBSEN, J.: Binding of bilirubin to human serum albumin: Determination of the dissociation constants. Fed. Eur. Biochem. Soc. Lett., 5: 112 (1969).

33. Kaplan, M., Straus, P., Bijaoui, G., and Bensadoun, M.: Maladie de Crigler et Najjar: Etude clinique et biologique d'une observation. Aspect du tissu hepatique au microscope electronique. Ann. Pediat., 13: 583 (1966).

34. Karon, M., Imach, D., and Schwartz, A.: Effective phototherapy in congenital nonobstructive, nonhemolytic jaundice. New Engl. J. Med., 282: 377 (1970).

35. Kline, W., and Rosenkranz, A.: Klinische und biochemische Studien zum Crigler-Najjar Syndrom. Mschr. Kinderheilk., 119: 555 (1971).

36. Kopelman, A. E., Brown, R. S., and Odell, G. B.: The "bronze" baby syndrome: A complication of phototherapy. J. Pediat., 81: 466 (1972).

37. Lester, R., Hammaker, L., AND Schmid, R.: A new therapeutic approach to unconjugated hyperbilirubinaemia. Lancet, ii: 1257 (1962). 
38. Lucey, J. F.: Phototherapy of jaundice 1969. In: D. Bergsma and D. Y.-Y. Hsia: Bilirubin Metabolism in the Newborn: Birth Defects, Vol. 6, p. 63 (Original Articles Series, 1970).

39. Lundh, B., Johansson, M. B., Mercke, C., and CavallinSTAHL, E.: Enhancement of heme catabolism by caloric restriction in man. Scand. J. Clin. Lab. Invest., 30: 421 (1972).

40. LyNCH, S. R., AND Moede, A. L.: Variation in the rate of endogenous carbon monoxide production in normal human beings. J. Lab. Clin. Med., 79: 85 (1972).

41. McKusick, V. A.: Discussion of Sleisenger, M. H., Kahn, I., Barniville, H., Rubin, W., BEN-Ezzer, J., and Arias, I. M.: Nonhemolytic unconjugated hyperbilirubinemia with hepatic glucuronyl transferase deficiency: A genetic study in four generations. Trans. Ass. Amer. Phys., 80: 259 (1967).

42. Micheli, F., And Dominici, G.: Recherches sur une forme d'ictere hemolytique congenital et familial avec bilirubinemie atypique. Sang, 6: 953 (1932).

43. Odell, G. B., Brown, R. S., And Holtzman, N. A.: Dye sensitized photo-oxidation of albumin associated with a decreased capacity for protein binding of bilirubin. In: D. Bergsma and D. Y.-Y. Hsia: Bilirubin Metabolism in the Newborn: Birth Defects, Vol. 6, p. 31 (Original Articles Series, 1970).

44. Odell, G. B., Brown, R. S., And Kopelman, A. E.: The photodynamic action of bilirubin on erythrocytes. J. Pediat., 81: 473 (1972).

45. Ostrow, J. D.: Photo-oxidative derivatives of $\left[{ }^{14} \mathrm{C}\right]$ bilirubin and their excretion by the Gunn rat. In: I. A. D. Bouchier and B. H. Billing: Bilirubin Metabolism (Blackwell Scientific, Oxford, 1967).

46. Ostrow, J. D.: Photocatabolism of labeled bilirubin in the congenitally jaundiced (Gunn) rat. J. Clin. Invest., 50: 707 (1971).

47. Ostrow, J. D.: Mechanisms of bilirubin photodegradation. Seminars Hematol., 9: 113 (1972).

48. Ostrow, J. D.: Photochemical and biochemical basis of the treatment of neonatal jaundice. In: $H$. Popper and F. Schaffner: Progress in Liver Diseases, Vol. IV (Grune and Stratton, New York, 1972).

49. Ostrow, J. D., and Branhan, R. V.: Photodecomposition of bilirubin and biliverdin in vitro. Gastroenterology, 58: 15 (1970).

50. Ostrow, J. D., Hammaker, L., and Schmid, R.: The preparation of crystalline bilirubin ${ }^{-14} \mathrm{C}$. J. Clin. Invest., 40: 1442 (1961).

51. Ostrow, J. D., And Schmid, R.: The protein-binding of ${ }^{14} \mathrm{C}$ bilirubin in human and murine serum. J. Clin. Invest., 42: 1286 (1963).

52. Peterson, R. E., and Schmid, R.: A clinical syndrome associated with a defect in steroid conjugation. J. Clin. Endocrinol., 17: 1485 (1957).

53. Plotz, P. H., Berk, P. D., Scharschmidr, B. F., Gordon, J. K., AND VERGALLA, J.: Removing substances from blood by affinity chromatography. I. Removing bilirubin anad other albuminbound substances from plasma and blood with albumin-conjugated agarose beads. J. Clin. Invest., 53: 778 (1974).

54. Poland, R. L., and Odell, G. B.: Physiologic jaundice: The enterohepatic circulation of bilirubin. New Engl. J. Med., 284: 1 (1971).

55. Poland, R. L., Avery, G. B., Goetcherian, E., and Odell, G. B.: Treatment of Crigler-Najjar syndrome with agar (Abstract). Pediat. Res., 6: 377 (1972).
56. Porto, S. O.: In vitro and in vivo studies of the effect of phototherapy on bilirubin. In: D. Bergsma and D. Y.-Y. Hsia: Bilirubin Metabolism in the Newborn: Birth Defects, Vol. 6, p. 83 (Original Articles Series, 1970).

57. Quarfordt, S. H., Hilderman, H. L., Valle, D., and Waddell, E.: Compartmental analysis of sulfobromophthalein transport in normal patients and patients with hepatic dysfunction. Gastroenterology, 60: 246 (1971).

58. Robinson, S. H.: Production and excretion of bilirubin in Gunn rats treated with phenobarbital. Proc. Soc. Exp. Biol. Med., 138: 281 (1971).

59. Rosenthal, I. M., Zrmmerman, H. J., and Hardy, N.: Congenital nonhemolytic jaundice with disease of the central nervous system. Pediatrics, 18 : 378 (1956).

60. Rugstad, H. E., Robinson, S. H., Yannoni, C., and Tashjian, A. H., JR.: Transfer of bilirubin uridine diphosphateglucuronyl transferase to enzyme-deficient rats. Science, 170 : $553(1970)$.

61. Scharschmidt, B. F., Plotz, P. H., Berk, P. D., Waggoner, J. G., AND Vergalla, J.: Removing substances from blood by affinity chromatography. II. Removing bilirubin from the blood of jaundiced rats by hemoperfusion over albumin-conjugated agarose beads. J. Clin. Invest., 53: 786 (1974).

62. Schmid, R., and Hammaker, L.: Metabolism and disposition of $\mathrm{C}^{14}$-bilirubin in congenital nonhemolytic jaundice. $\mathrm{J}$. Clin. Invest., 42: 1720 (1963).

63. Sleisenger, M. H., Kahn, I., Barniville, H., Rubin, W., BenEZZER, J., AND ARIAS, I. M.: Nonhemolytic unconjugated hyperbilirubinemia with hepatic glucuronyl transferase deficiency: A genetic study in four generations. Trans. Ass. Amer. Phys., 80: 259 (1967).

64. Song, G. S., Gelb, N. A., ANd WolfF, S. M.: The influence of pyrogen induced fever on salicylamide metabolism in man. J. Clin. Invest., 51: 2959 (1972).

65. Starzi, T. E., Halgrimson, C. G., Francavilla, F. R., Porter, K. A., Brown, T. H., And Purnam, C. W.: The origin, hormonal nature, and action of hepatotrophic substances in portal venous blood. Surg. Gynec. Obstet., 137: 179 (1973).

66. Starzl, T. E., and Purnam, C. W.: Experience in Hepatic Transplantation (W. B. Saunders, Philadelphia, 1969).

67. Szabo, L., ANd Fbrey, P.: Studies on the inheritance of CriglerNajjar syndrome by the menthol test. Acta Paediat. Hung., 4: 153 (1963).

68. Thompson, R. P. H., Eddleston, A. L. W. F., ANd Williams, R.: Low plasma-bilirubin in epileptics on phenobarbitone. Lancet, $i: 21$ (1969).

69. Trolle, D.: Decrease of total serum-bilirubin concentration in newborn infants after phenobarbitone treatment. Lancet, ii: 705 (1968).

70. Weber, A. P., ANd Schalm, L.: Quantitative separation and determination of bilirubin and conjugated bilirubin in human serum. Clin. Chim. Acta, 7: 805 (1962).

71. Whrringron, G. L.: Congenital nonhemolytic icterus with damage to the central nervous system. Report of a case in a Negro child. Pediatrics, 25: 437 (1960).

72. International Business Machines/National Cancer Institute.

73. We are indebted to Drs. Robert Graw and Geoffrey Herzig, Pediatric Oncology Branch, National Cancer Institute, for performing the exchange plasmaphereses.

74. Westinghouse Electric Corporation, Pittsburgh, Penn.

75. We are grateful to Dr. Guy McKhann, Professor of Neurology, 
Johns Hopkins University School of Medicine, for his assistance in evaluation of this patient.

76. The patient was taking diphenylhydantoin and ethosuximide throughout this study.

77. We are indebted to Dr. Chull Song for analysis of these specimens, and for many helpful suggestions.

78. Abbott

79. We are grateful to Dr. James Knepshield, Walter Reed Army Institute of Research, for making available and operating the artificial kidney in these experiments.

80. We are deeply indebted to Dr. Paul H. Plotz of the Arthritis and Rheumatism Branch of the NIAMDD for preparation of the albumin-agarose columns and for his continued advice and assistance with this aspect of the study.

81. The authors are deeply indebted to the staffs of the 2-East Nursing Unit, the Blood Bank and the Clinical Pathology
Department of the National Institutes of Health Clinical Center for their superb support in the care of this patient. We are also most appreciative of the advice and suggestions about numerous aspects of this problem offered by Drs. Irwin $M$. Arias, Martin Black, Barbara 'H. Billing, John F. Crigler, Jr., Burton Combes, Jerold F. Lucey, Gerard B. Odell, J. Donald Ostrow. Bernard Patten, Stephen H. Robinson, F. Lee Rodkey, Rudi Schmid, Samuel Schwartz, Sheila Sherlock, Thomas R. C. Sisson, Thomas E. Starzl, M. Michael Thaler, Cecil J. Watson, and Sumner J. Yaffe. Special thanks are also due to Dr. Nathaniel I. Berlin for his continuing assistance and advice in the management and evaluation of this patient.

82. Requests for reprint should be addressed to: P. D. BERK, M.D., Section on Diseases of the Liver (NIAMDD), Bldg. 10, Rm. 4D-52, NIH, Bethesda, Md. 20014 (USA).

83. Accepted for publication January 12, 1974. 